\title{
Paste and Thickened Tailings and the Impact on the Development of New Rheological Techniques
}

\author{
D.V. Boger Department of Chemical and Biomolecular Engineering, University of Melbourne, Australia \\ P.J. Scales Department of Chemical and Biomolecular Engineering, University of Melbourne, Australia
}

F. Sofra Rheological Consulting Services Pty Ltd, Australia

\begin{abstract}
The shift from pumping low-concentration Newtonian fluid tailings suspensions to disposal to the production of non-Newtonian paste and thickened tailings has meant that the minerals and energy industries have had to learn how to handle (dewater, pump, and deposit) non-Newtonian materials. Such high concentration, non-ideal (dirty) suspensions has meant that new rheological methods and techniques were needed for both shear and compression to measure and interpret the basic flow properties of paste and thickened tailings. Also, some older empirical techniques needed to be modified and interpreted in a more fundamental way so that the results could be used in design. The paper reviews these rheological techniques and illustrates how the industry itself has motivated their development.
\end{abstract}

\section{Introduction}

In 1974 the first author (Boger) was approached at Monash University by Peter Colombera and Mark Want from Alcoa of Australia with an enquiry about the rheological characteristics of the material they called "red mud". At this time the research in rheology at Monash had been ongoing only for about six years and was almost entirely related to the behaviour of polymers. It was, however, obvious after talking to Alcoa, Australia that the material they were looking at exhibited thixotropic characteristics and it seemed as if the breakdown in structure associated with thixotropy in shear occurred at a more rapid rate than the rebuilding of that structure. In ideal thixotropic behaviour the two timescales are the same and there is no difference between breakdown and structural recovery. The enquiry was made by Alcoa because of the realisation that the current practice, which was pumping the red mud to the disposal area at a concentration of between $15-20 \%$ by weight solids as a Newtonian fluid, at a $\mathrm{pH}$ of 13 , into lakes of about 250 ha in area, was presenting a problem; in fact, there was evidence that the lakes were leaking caustic into the ground water. They were motivated therefore to look at techniques whereby the mud would be dewatered and handled at as high a concentration as possible. They needed to understand the rheological characteristics of this material! Preliminary investigation determined that at low concentrations, i.e. at the level at which they were pumping, the material exhibited Newtonian fluid behaviour, while at higher concentrations, non-Newtonian shear thinning characteristics and a yield stress were observed. At even higher concentrations thixotropy was observed. Figure 1 shows shear stress-shear rate data for a concentrated red mud suspension after being subjected to significant periods of shear with a helical ribbon mixer. The thixotropic characteristics of the material are obvious as the shear stress at a particular shear rate decreases significantly with mixing time. Figure 2 illustrates the behaviour more graphically, where a filter cake is shown which can be formed into a spherical shape which, after mixing, flows like a paste. 


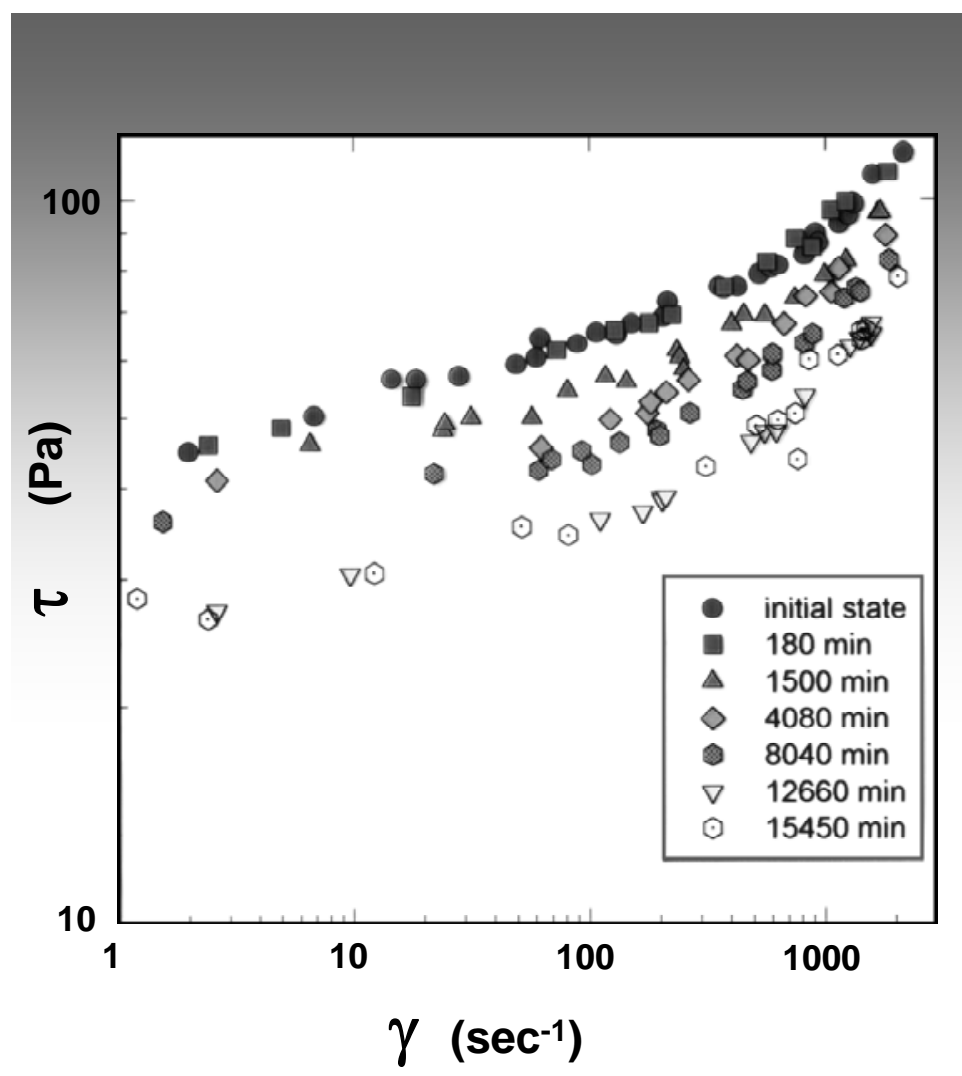

Figure 1 Typical red mud shear stress-shear rate behaviour illustrating thixotropic behaviour. The data were obtained after shearing the mud at high shear rate for different times

What was also apparent simply by examining the mixing process was that the structural breakdown process occurred far more rapidly than the restructuring process. Thus it appeared as if one could exploit the thixotropic characteristics in the transportation of a high concentration mud to the disposal area, i.e. dewater the material by "brute force", shear the "hell" out of it to break the structure, then transport it out to the tailings facility where the material would restructure slowly. To quantify this behaviour a single point flow property measurement was required. It was from this observation that the vane device was adopted from soil mechanics by Professor Dzuy Nguyen in his PhD thesis (Nguyen, 1983) and developed for the single point measurement of the rheological yield stress, a fundamental fluid property. Some very early data obtained with the vane showing the breakdown and recovery of the red mud are shown in Figure 3 . While the timescale of the breakdown process is measured in hours, the recovery process is measured in days, and the parameter used to establish this behaviour was the yield stress measured originally with the vane device. The vane was a perfect instrument to examine the thixotropic characteristics of the red mud. It also became apparent that once the material reached an equilibrium state in shear it took a long time for the recovery to take place and one could define the equilibrium shear stress-shear rate data, or the equilibrium viscosity shear rate data. Such results as a function of concentration are shown in Figure 4. The shear thinning characteristics of the material are apparent as the concentration increases, from Newtonian behaviour at the lowest concentration (36.2\%) by weight. Data like that shown in Figures 1, 3 and 4 formed a basis for understanding how to handle, pump, and produce the higher concentration material. Alcoa went through all sorts of piloting processes to look at various dewatering devices and eventually ended up with the super thickeners which they now use today in their dry stacking technology. 


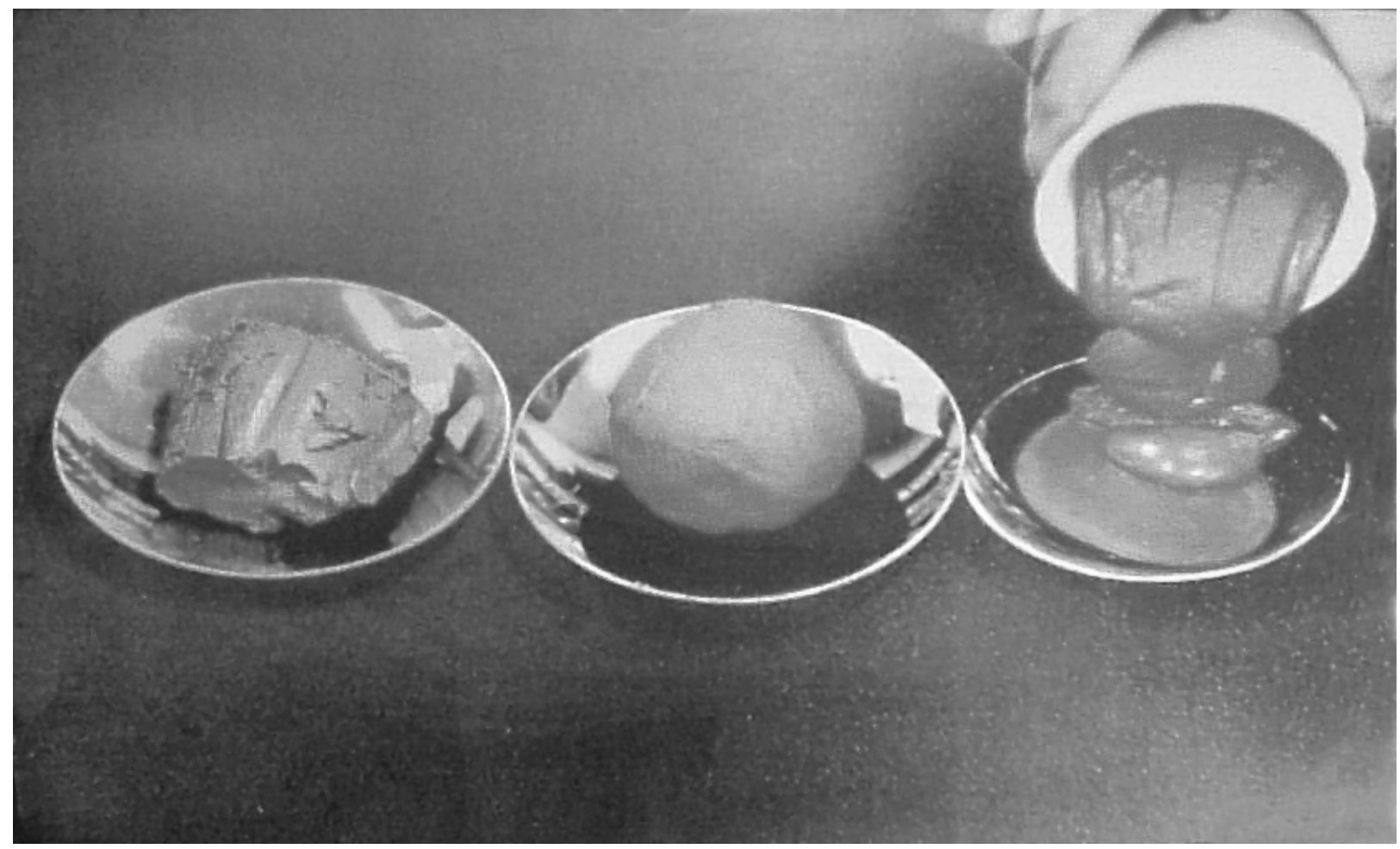

Figure 2 Illustration of the effect of shear on a red mud filter cake

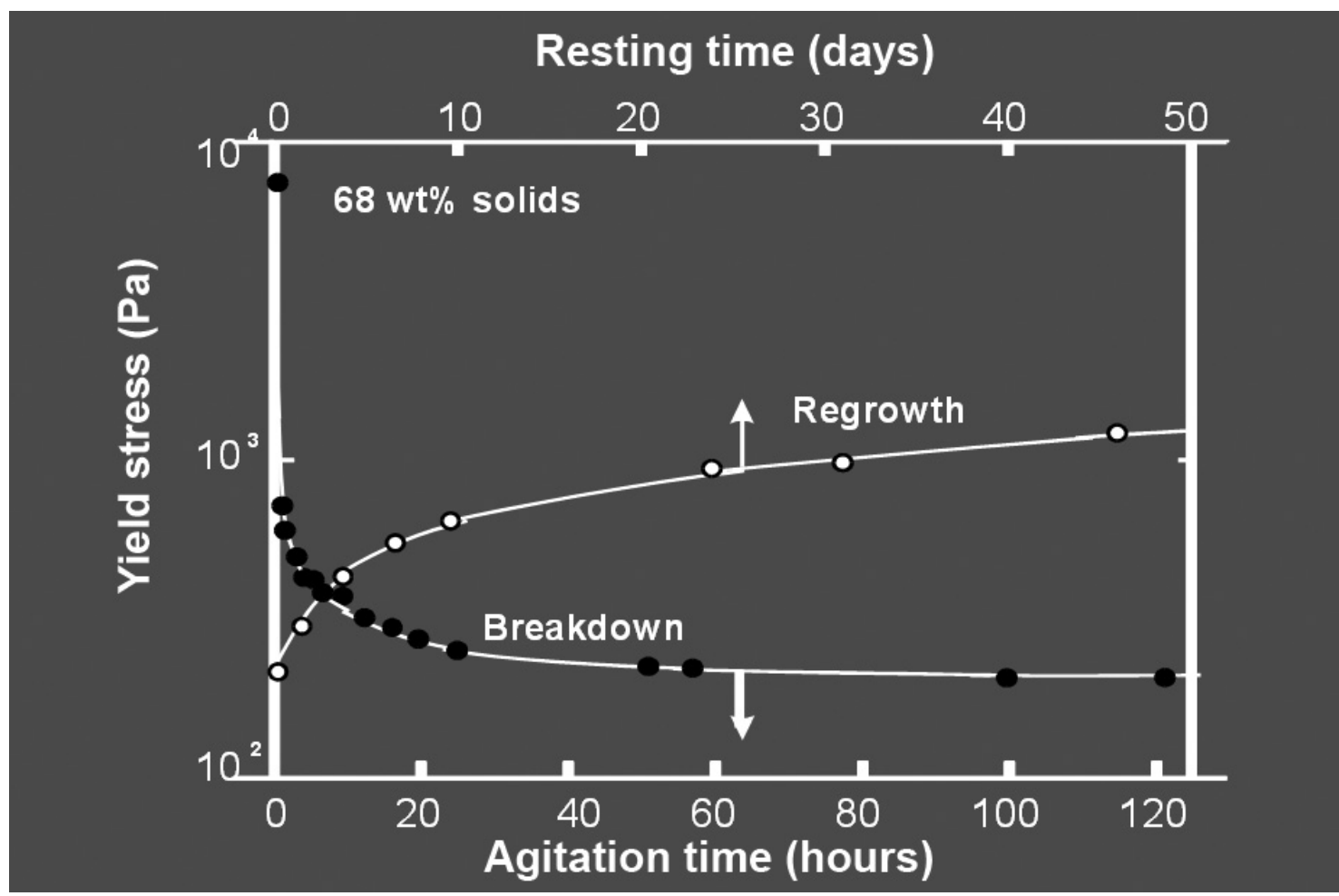

Figure 3 Use of the vane yield stress measurement to illustrate the breakdown and recovery of the red mud structure 


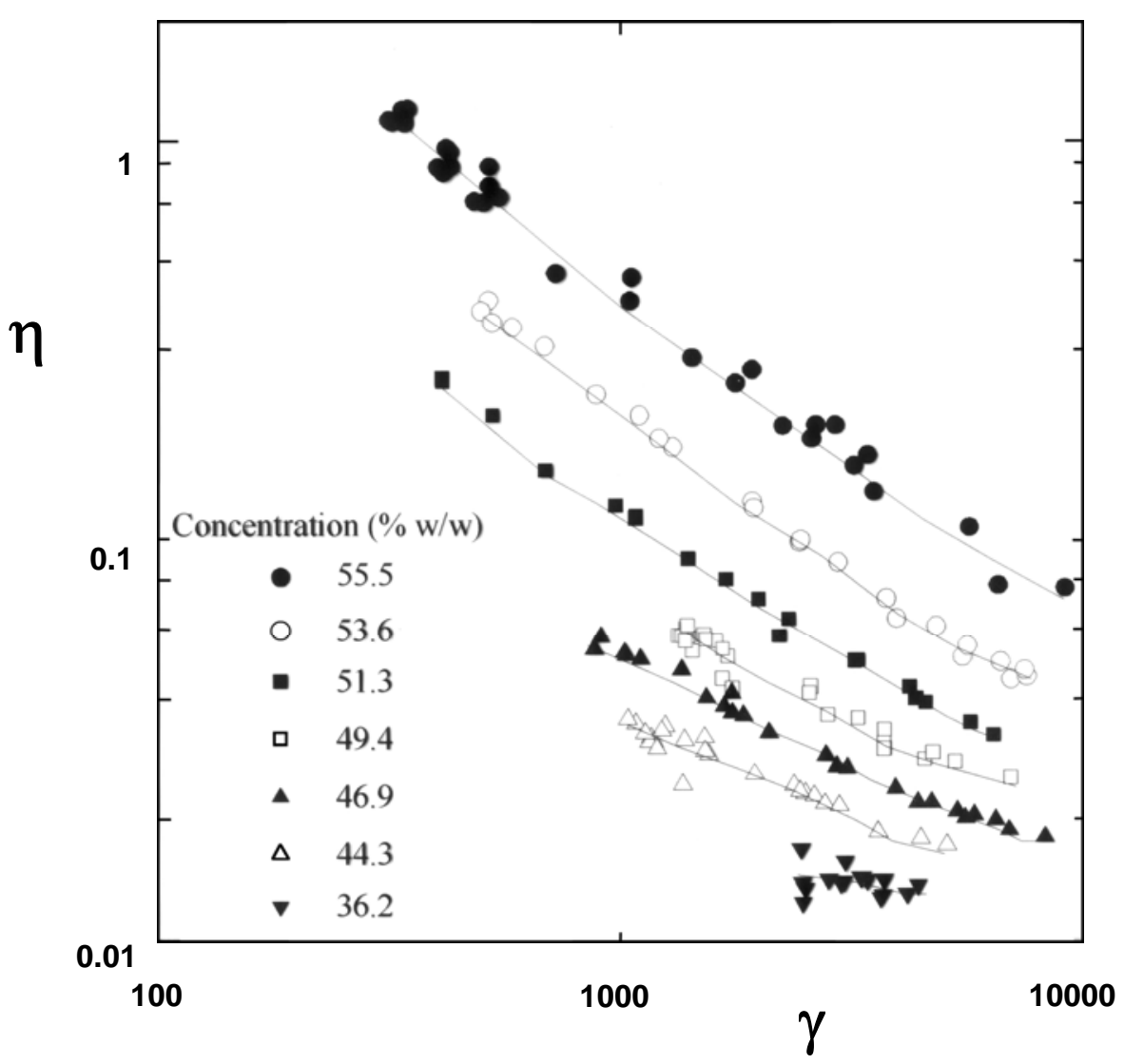

\section{Figure 4 Red mud equilibrium viscosity shear rate data}

The impact of the alumina industry on our research was immense because it became apparent that techniques were required for measuring the flow characteristics of these concentrated suspensions and one needed to understand yielding and thixotropic behaviour. Also, once the techniques were developed one could start making comparisons across this industry and others. For example, Figure 5 illustrates the different red muds at the Alcoa Kwinana refinery in Western Australia, the Port Comfort refinery in the USA, and the refinery in Jamaica, with the yield stress forming a basis for comparison which, of course, is now used in the minerals industry as a whole to construct graphs like that shown in Figure 5 (see Figure 3.8, Boger et al., 2006 and Figure 1.5, Jewell and Fourie, 2006).

The alumina industry was the first to discover and exploit an understanding of basic rheology in the handling of its waste. The rest of the story is history. After the original consulting work, six PhD students worked on the problem at Monash and then Melbourne Universities: Dr Guillermo Sarmiento on the rheology of lower concentration red muds; Professor Q D Nguyen, who amongst other things established the vane device for yield stress measurement; Dr N J de Guingand, who was the first student to work on the compression characteristics of red mud; Dr Nick Pashias, who did a comparative study of the red muds across the Alcoa organisation and established the slump technique for yield stress measurement; Dr Fiona Sofra worked on the stacking angles for red mud. Dr David Cooling was the final PhD student (Cooling, 2005), whose work was conducted at the refinery itself and was used to prove established methods for sequestering $\mathrm{CO}_{2}$ in the red mud. David Cooling had a huge impact earlier on because it was his Masters thesis from Curtin University of Western Australia (Cooling, 1983) which formed a basis for Alcoa moving to the use of super thickeners. 


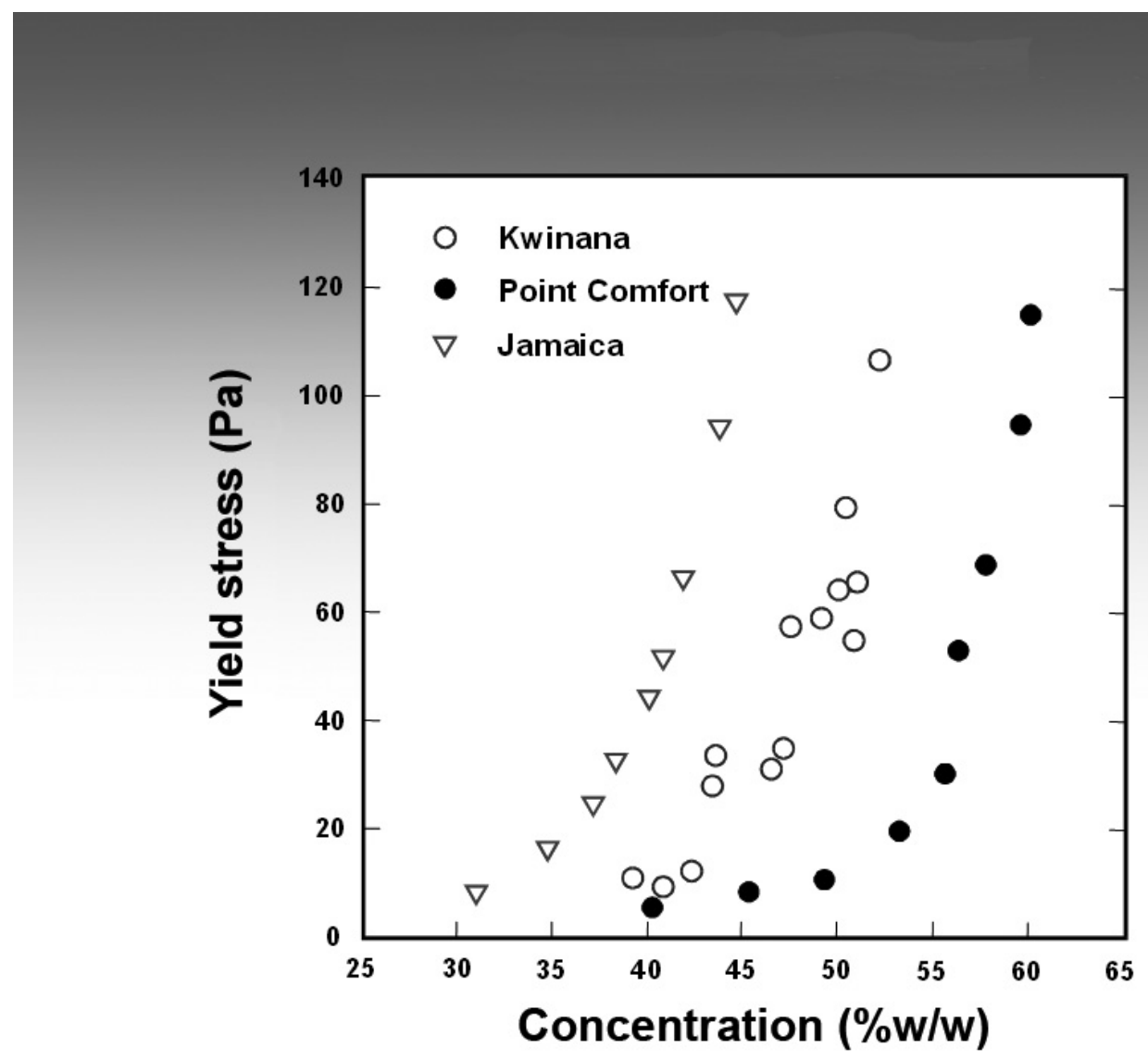

Figure 5 Yield stress as a function of concentration for various red mud samples

It was in 1998 after being a speaker at the Sixth International Symposium on Mining and Backfill held in Brisbane, Queensland that it became obvious to the authors that those who were interested in making a paste backfill didn't realise that the alumina industry was making the same sort of material for distribution on the surface. It also was obvious that we were not aware of some the large international problems in the mining industry associated with the management of waste. At that time it was thought that $15,000 \mathrm{t} /$ day on a dry basis, which represented an average sort of figure for the alumina industry, represented a large amount of waste. Little did we know until attending the First Paste and Thickened Tailings Seminar that the copper industry, and for that matter the oil sands industry, were producing in excess of 200,000 t/day from one operation. It has been through the paste and thickened tailings seminars extending back to the year 2000 in Perth, Western Australia, that rheology has been introduced to the minerals industry as a whole. The impact that rheology has had on the industry and the impact that the industry has had on developments in rheology has been significant. The purpose of this paper is to review developments in rheology which were a direct response to the needs of the minerals industry, and in particular, to the needs associated with waste disposal, but now including issues like suspension feeds in mineral processing (nickel laterite, etc.).

\section{Basic rheological properties}

For the suspensions encountered in paste and thickened tailings, non-Newtonian characteristics are generally observed at higher concentrations. The basic measurements required to characterise these materials include the viscosity and how it varies with shear rate (flow rate). The general definition of the viscosity is:

$$
\eta=\frac{\tau}{\dot{\gamma}}
$$


where $\tau$ is the shear stress and $\dot{\gamma}$ is the shear rate. In order to make this basic measurement one must use a characterisation device where both the shear stress and the shear rate can be defined. This science is called rheometry. There are basically four flow fields called viscometric flows where the shear stress and the shear rate can be defined and hence one can define the viscosity for a non-Newtonian material. These flow fields are shown in Figure 6. Each of these flows has its own significant advantages and disadvantages. Poiseuille flow involves measuring the pressure drop as a function of flow rate in a long straight tube; special capillary rheometers can be designed to make these measurements but the measurements can be labour intensive and often are associated with significant problems at the wall of the tube where slip can occur.

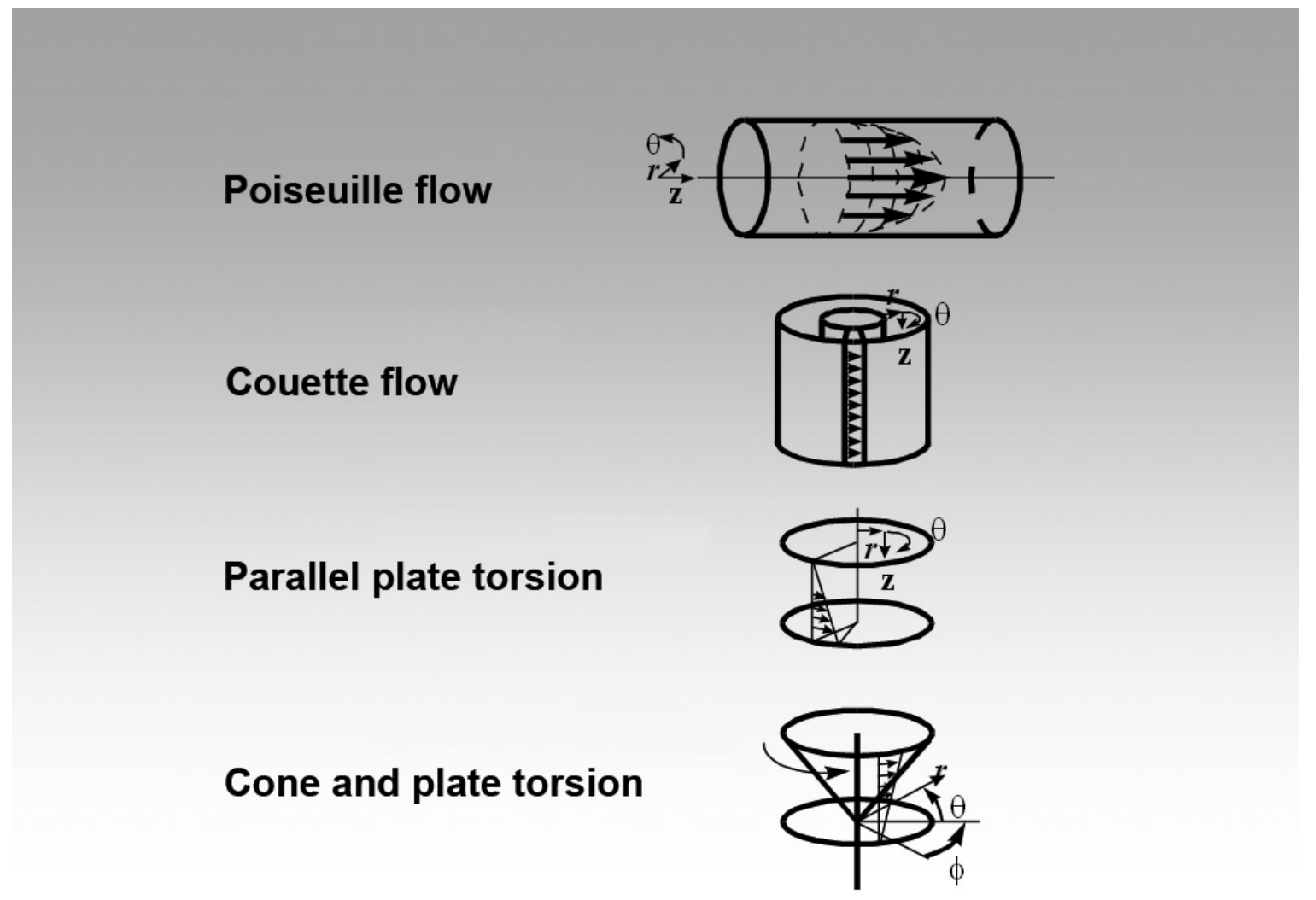

Figure 6 Viscometric flows used for viscosity measurement of non-Newtonian fluids

The most common geometry used for measurement of shear stress and shear rate is Couette flow - a cup and bob rheometer. This geometry also has a distinct disadvantage in that the gap has to be large enough so that the particles themselves don't interfere with the measurement. When the gap is large the analysis of data becomes complex and often is not understood. Slip is a problem and sedimentation can also occur. Almost no-one uses parallel plate torsion flow geometry for measurements of suspensions; again the problems are associated with sedimentation and slip and analysing the basic data. Cone and plate torsion flow, although good for measuring the properties of polymers and polymer solutions, again the gap in the instrument has to be very small for the analysis to be correct. Hence none of the above geometries, which form the basis of some very sophisticated and expensive instruments, are readily suitable for the measurements of the basic viscosity of a paste material. Yield stress measurements with conventional rheometric equipment can be equally as problematic.

\subsection{Yield stress measurement}

Figure 7 illustrates typical shear stress-shear rate behaviour that is observed for a yield stress material. There are very significant misconceptions associated with yielding. Much of the data obtained for suspensions is unable to reach low enough shear rates to determine a true yield stress by extrapolation. Often the data are extrapolated from a linear region of behaviour at high shear rates to the axis to define what which has been called the Bingham yield stress. The Bingham yield stress is a model fitting parameter and has no meaning whatsoever in terms of the true yielding of the material. We have seen many consulting reports in which this 
yield stress has been used as a basis for design. The yield stress is the value of the shear stress when the material initially flows, and in principal can be determined if the measurements of the shear stress as a function of shear rate are made at low enough shear rates. However, there are difficulties in reaching such low shear rates, as slip invariably occurs in the concentric cylinder geometry at low shear rates. Thus extrapolated values of the shear stress-shear rate data are not easy to obtain and are often in significant error. Figure 8 illustrates the potential errors associated with extrapolation, dependent upon the shear rate region in which data are available.

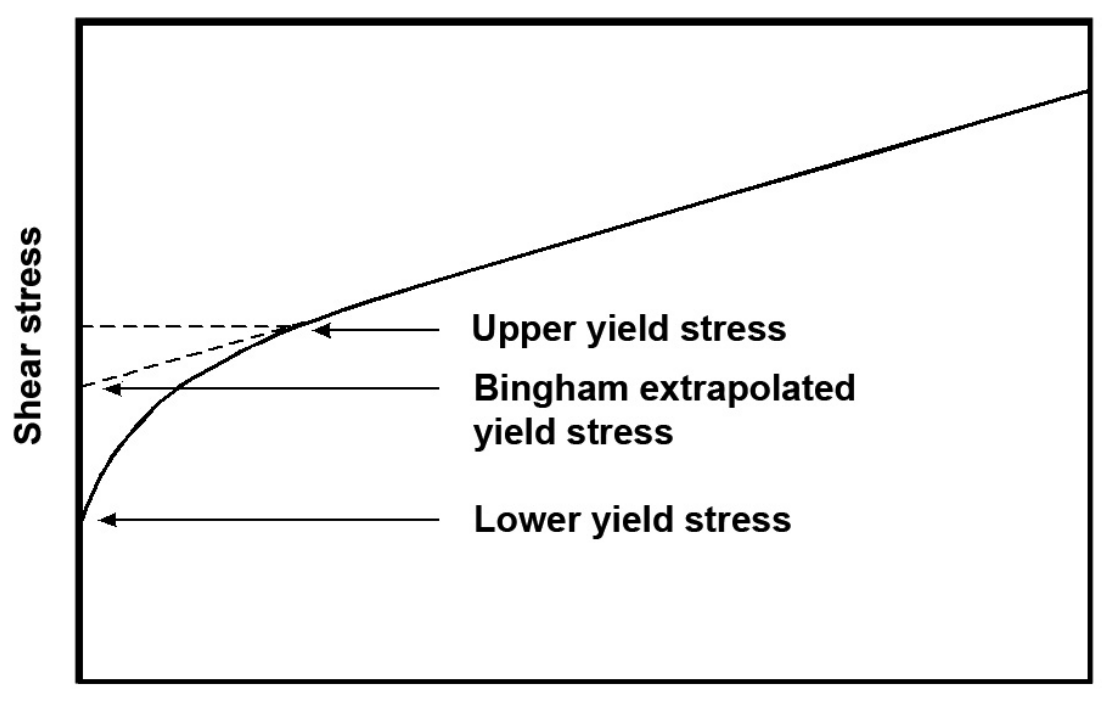

0

Shear rate

Figure $7 \quad$ Typical shear stress-shear rate behaviour illustrating the "yield stress"

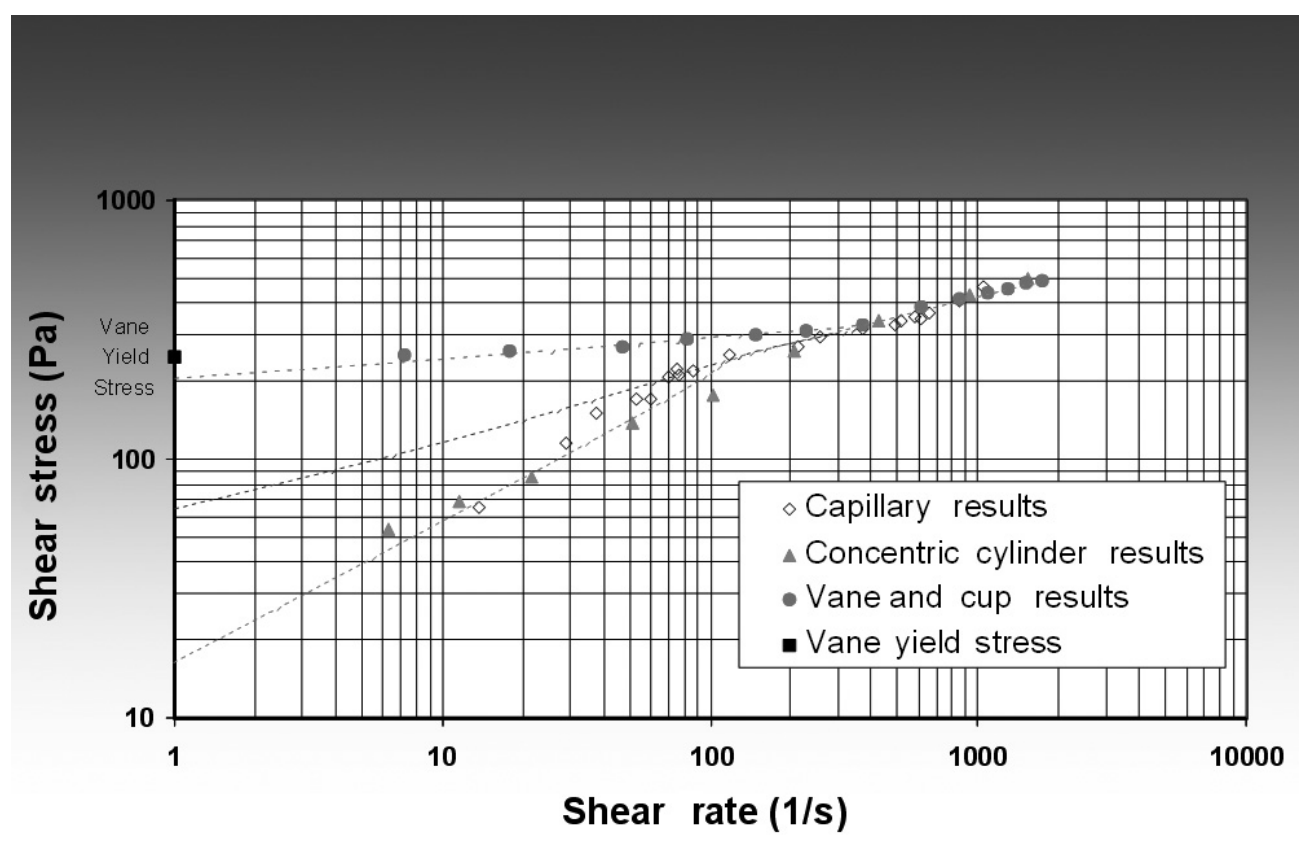

Figure 8 Flow curve for a paste sample - yield stress $=250 \mathrm{~Pa}$

The true yield stress for the mine stope fill material shown in Figure 8 was obtained with the vane. The extrapolation of the high shear rate data obtained and reproduced with a capillary and concentric cylinder 
device is $65 \mathrm{~Pa}$, while the extrapolated value obtained from the lower shear rate data is on the order of $18 \mathrm{~Pa}$. The true yield stress was $250 \mathrm{~Pa}$ ! The errors involved are immense and thus, if the true yield stress is needed, which is the case for rake design in thickeners and for pump re-startup and design in a pipeline, then conventional rheometry geometry generally should not be used and a device like the vane is appropriate. As already stated, the vane and its use for yield stress measurement in suspensions was developed by Q D Nguyen in his PhD thesis in 1983 (Nguyen and Boger, 1983, 1985). The basic vane and the principles involved are illustrated in Figure 9, while the basic equation for analysing the data is given in Equation 2.

$$
T_{m}=\frac{\pi}{2} d^{3}\left(\frac{l}{d}+\frac{1}{3}\right) \tau_{y}
$$

Basically, the vane is inserted into the suspension and rotated at a very low speed where the torque is observed as a function of time. The torque increases until reaching a maximum value, $T_{m}$, when the material yields. The maximum torque is related to the yield stress by Equation 2, where $d$ is the diameter of the vane and $l$ is its height. Equation 2 is valid if end effects are minimised and this is possible by using a large enough $l / d$ vane. The great advantage of the vane is the material yields on itself, slip generally is not an issue, and also, the vane can be inserted into the fluid in different regions. This technique is now used worldwide for measurement of yielding in all matter of materials. The development of the technique was motivated by a need generated by the alumina industry.

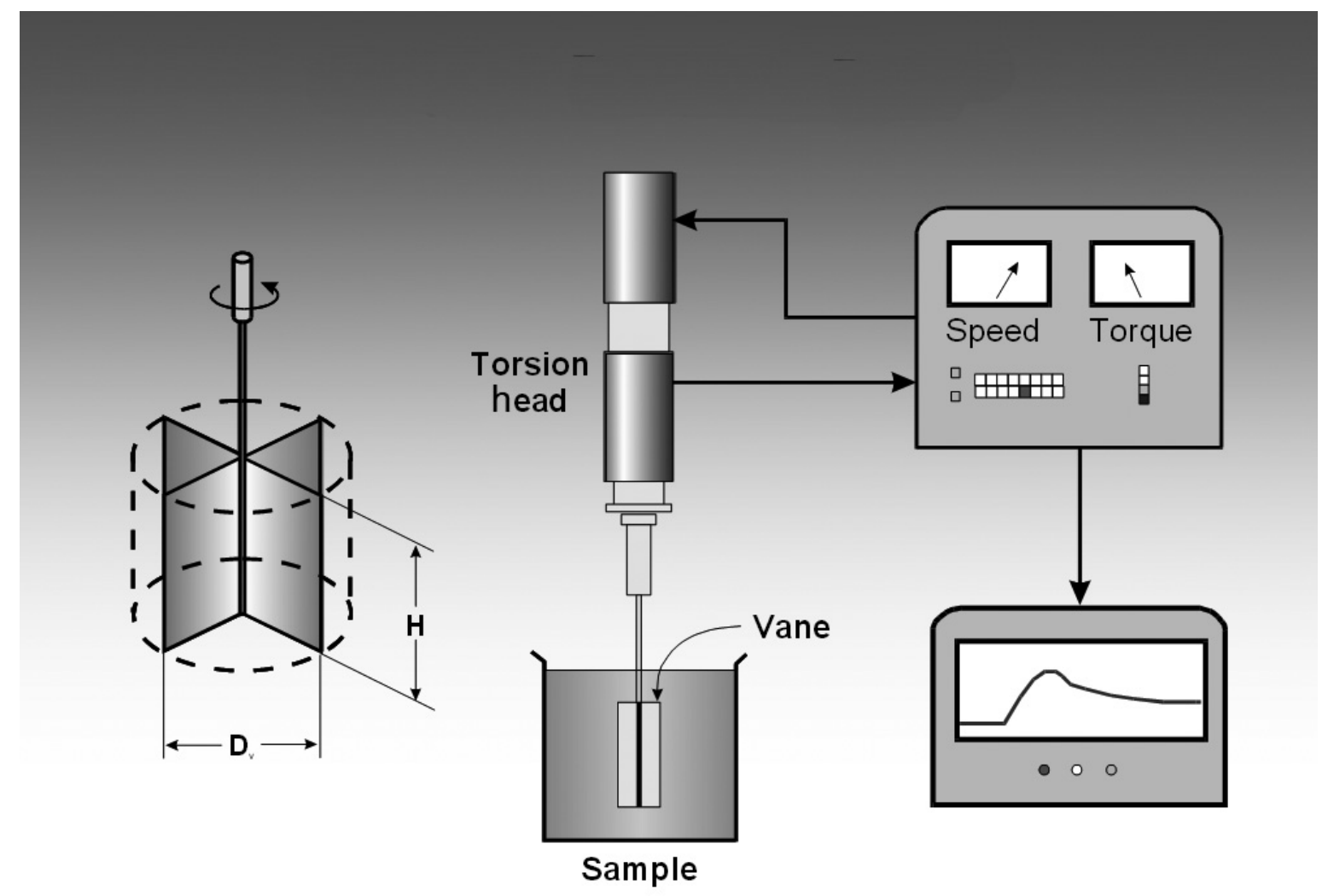

\section{Figure 9 Illustrating the vane device for yield stress measurement}

Another even simpler method for a single point measurement of the yield stress is to exploit slump. The civil engineering community for many years has used a conical device for measuring the slump in concrete. The results of such measurements were reported in inches or centimeters of slump and were not related to any fundamental characteristic. Nick Pashias in his PhD thesis (Pashias, 1997) took the idea of the slump, simplified the geometry to a cylindrical geometry and established a simple equation for relating the slump to the yield stress. Figure 10 illustrates how the slump is measured while Equation 3 is a simple interpretation of the slump measurement. 


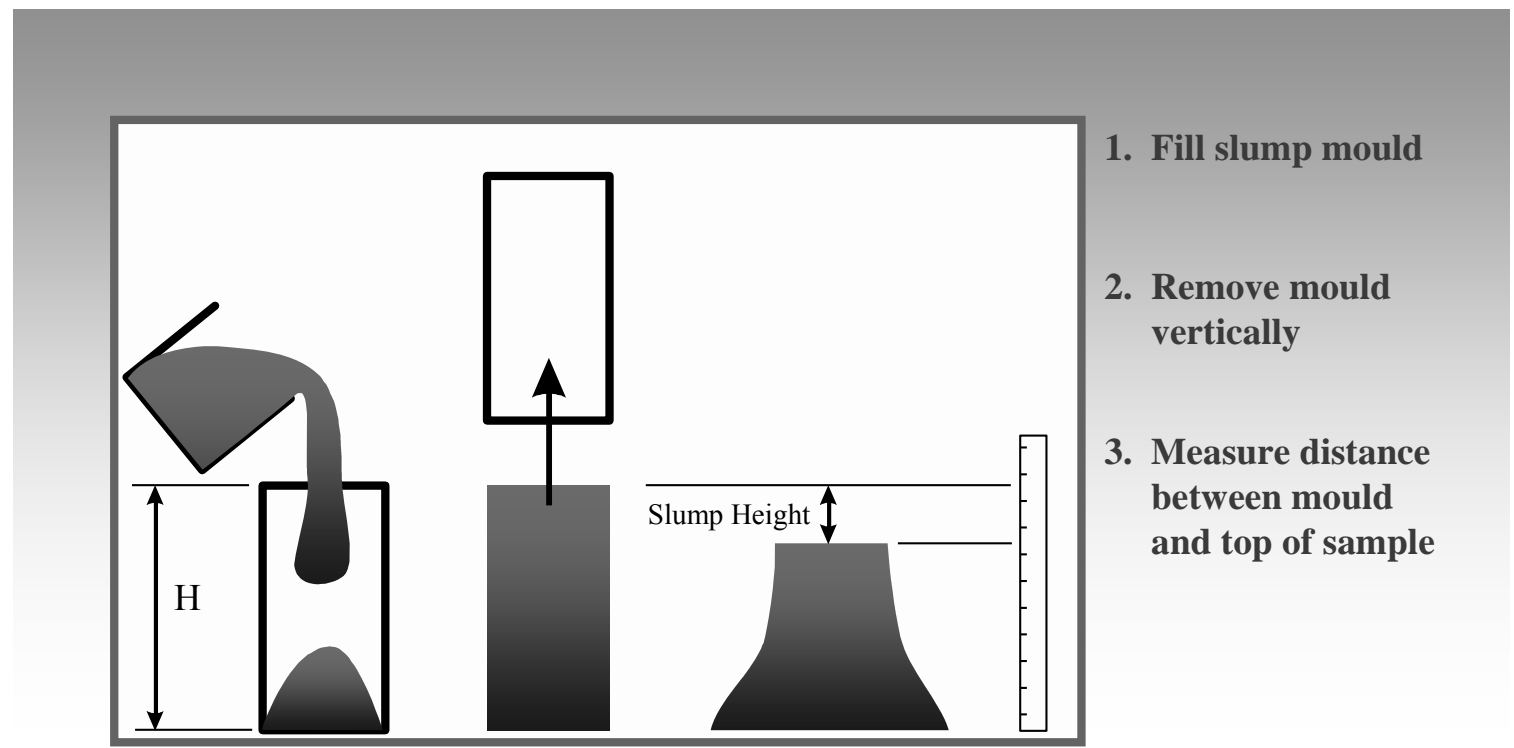

Figure 10 The cylindrical slump test

$$
\tau_{y^{\prime}}=\frac{1}{2}+\frac{1}{2} \sqrt{S}
$$

$\tau_{y^{\prime}}$ is a dimensionless slump $\left(\tau_{y^{\prime}}=\frac{\tau_{y}}{\rho g H}\right)$, and $S$ is the dimensionless slump which is the actual slump divided by the height of the cylindrical slump vessel, $H$. Numerous direct comparisons of the cylindrical slump measurement and the vane yield stress measurement are now available in the literature (Piau, 2005; Boger et al., 2006). The slump measurement was again motivated by the alumina industry and in particular, from a discussion with Don Glenister. Thus the alumina industry and the basic properties of the red mud motivated the development of two methods for single point yield stress measurement which are now used industry-wide and extend well beyond the industry into the world as a whole. On the basis of experience gathered with the alumina industry and with the minerals industry as a whole, it was obvious that a simple and perhaps even more effective method for determining the basic shear stress-shear rate data was needed.

\subsection{Shear stress-shear rate measurements (the bucket rheometer)}

The Couette viscometer is the instrument most commonly used for obtaining the shear stress-shear rate data for many materials and in many industries. The torque, $T$, on the bob is observed as a function of its rotational speed $\Omega$. The basic equations used to analyse the data are Equation 4 for the shear stress at the two surfaces and Equation 5 for the shear rate.

$$
\begin{gathered}
\tau_{1}=\frac{T}{2 \pi R^{2}} L=\varepsilon^{2} \tau_{2} \\
\Omega=\int_{\tau_{2}}^{\tau_{1}} \frac{f(\tau)}{2 \tau} d \tau
\end{gathered}
$$

In the equations, $\tau_{1}$ and $\tau_{2}$, are the shear stresses at the surfaces of the bob $(\mathrm{r}=R)$ and the cup $(\mathrm{r}=\varepsilon \mathrm{R})$ and $f$ $(\tau)$ is the shear rate, $\dot{\gamma}$. Note in Equation 5 that the shear rate is hidden inside an integral. The fact that the shear rate is not explicitly defined causes some considerable difficulties in analysing the data. Integration of Equation 5 depends on knowing a functional form between the shear stress and shear rate, i.e. substituting a fluid model. Such a model will not be available a priori hence approximate techniques are needed to 
evaluate the shear rate in the cup and bob rheometer, particularly when the gap is wide, which is necessary for paste or suspension-like material that are of interest here. Often a narrow gap assumption is made in order to define the shear rate simply by Equation 6 . This definition, often embedded in instrument software, is not valid for the wide gap required when dealing with paste-like systems.

$$
\dot{\gamma}_{1}=f\left(\tau_{1}\right)=\frac{2 \Omega}{\left(1-\varepsilon^{2}\right)}
$$

Kreiger and Maron (1954) were the first to realise that Equation 5 could be differentiated on both sides with respect to $\tau_{1}$ if the outer radius of the cup becomes very large (goes to $\infty$ ). The result of this differentiation on both sides yields to the simple result given by Equations 7 and 8 .

$$
\begin{aligned}
& \tau_{1}=\frac{T}{2 \pi L R^{2}} \\
& \dot{\gamma}_{1}=\frac{2 \Omega}{S_{1}}
\end{aligned}
$$

Where

$$
S_{1}=\frac{d \ln T}{d \ln \Omega}
$$

The shear stress and the shear rate on the inner bob surface rotating in an infinite medium is now directly defined and not dependent on any particular model assumption. The procedure is as follows. The torque is measured as a function of rotational speed and plotted on a log-log graph. Generally, the slope of this graph will be a constant $S_{1}$. Once $S_{1}$ is known the shear rate is defined, as is the shear stress, from the torque measurements. The idea of a bob in an infinite medium has been a relatively obscure concept. Combining this analysis with the idea of using the vane itself as a rotational device results in a new rheometer. The vane itself has a distinct advantage that effectively slip is eliminated. Using the vane as the "rotating" bob allows measurements to be made in the absence of slip. Barnes and Carnali (1990) have shown, while working in the food industry, that the vane in fact can be used as a rotational device and functions as a bob, particularly for shear thinning materials. The advantages of the vane rotating in an infinite medium, i.e. in a bucket of fluid, are obvious. All that is required is a vane and a torque measuring head and hence the device is portable. Additionally the shear stress and the shear rate data are easily determined. It should be noted that Equations 7,8 and 9 are also valid for yield stress materials. The idea of the bucket rheometer has been published (Fisher et al., 2007; Sofra et al., 2007). Figure 11 illustrates some data obtained for a nickel laterite slurry, which is the feed to the extraction process. The figure illustrates the regions in which the data would be required and also illustrates clearly the slip problems associated with the cup and bob instrument and the capillary instrument. Also note that the vane and cup rotation device extrapolates to the vane yield stress measurement. Other data illustrating the applicability of the bucket rheometer are available (Fisher et al., 2007). 


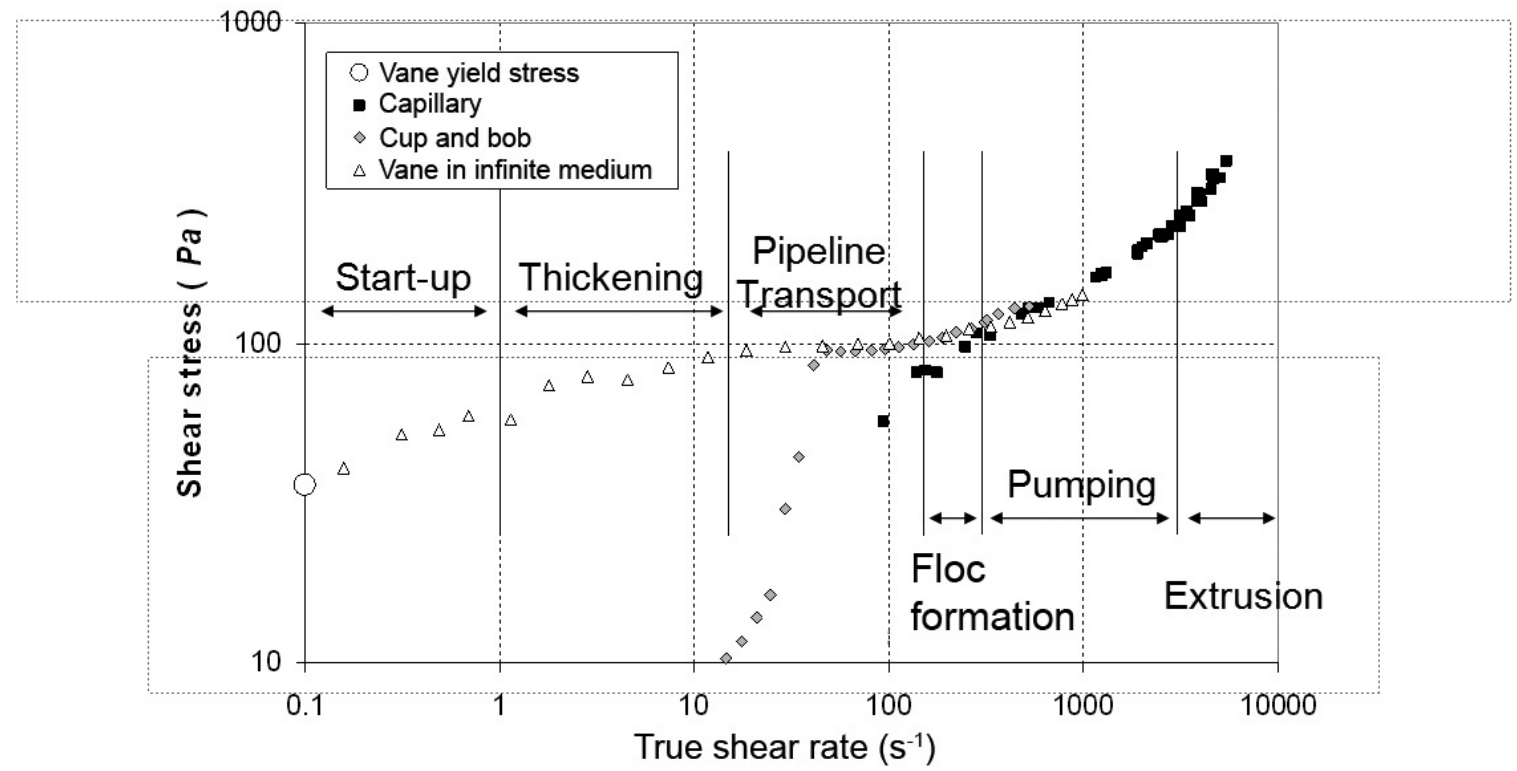

Figure 11 Shear stress-shear rate data obtained for a $45.1 \mathrm{w} / \mathrm{w}$ limonite slurry illustrating the performance of the bucket rheometer

\subsection{Rheological flow properties in compression - the compressive yield stress and the permeability}

Motivated by basic research, by the theoretical work of Buscall and White (1987), and by observations at Alcoa on development and use of the super thickeners, where a six metre compression zone was used in a $90 \mathrm{~m}$ thickener, it was clear that there must be a better way to evaluate how a flocculated suspension would behave in compression. This led to a series of $\mathrm{PhD}$ theses at the University of Melbourne starting with the Masters thesis of Nick de Guingand in 1986, the PhD thesis of Matt Green in 1997, continuing through the work of Shane Usher in 2002, and Brendan Gladman in 2006. The overall result of the research carried on at the University of Melbourne has lead to the development of a new instrument for measuring the compression rheological properties of flocculated suspensions. This instrument is now available commercially. A review paper published in 2003 (de Kretser et al., 1983) summarises the earlier work. Current research is on understanding the influence of shear on the compression of flocculated suspensions. Professor Peter Scales presented an overview of this work at the Paste and Thickened Tailings seminar in Ireland in 2006 (Gladman et al., 2006), which will not be reviewed here. Recent references are available (Gladman et al., 2006; Usher and Scales, 2005; and Gladman et al., 2005). Suffice to say that this is yet another area of research which was motivated initially by the involvement with Alcoa in Western Australia. The impact in the industry has been significant and active research in this area continues today.

\section{Conclusion}

Academic research is often driven by curiosity while industrial research is often driven by need. The paper illustrates how academic research in non-Newtonian fluid mechanics (rheometry) has been motivated and influenced by an industrial need. The outcome has been the development of two techniques for yield stress measurement and a simple and portable technique for viscosity measurement in non-Newtonian fluids. In particular, the techniques are applicable to what we might call "dirty suspensions" or "real suspensions" which could have a significant variation in particle size and where the interest is primarily in determining the properties at high concentration. The impact in the paste and thickened tailings community has been significant, as is evidenced in this seminar where again a special session has been devoted to rheology. 


\section{References}

Barnes, H.A. and Carnali, J.O. (1990) The vane-in-cup as a novel rheometer geometry for shear thinning and thixotropic materials, J. Rheol., 34(6), p. 841.

Boger, D.V., Scales, P.J. and Sofra, F. (2006) Rheological concepts, Paste and Thickened Tailings - A Guide, Second Edition, Jewell and Fourie (eds), Australian Centre for Geomechanics, Perth, Australia, p. 25.

Buscall, R. and White, L.R. (1987) The consolidation of concentrated suspensions, Part I: The theory of sedimentation, Chem. Soc. Faraday Trans. I, 83, p. 873.

Cooling, D.J. (1983) Fine grained consolidation of red mud from the alumina industry, M.App.Sc Thesis, Curtin University, Perth.

Cooling, D.J. (2005) Improving the sustainability of bauxite residue management, PhD Thesis, The University of Melbourne.

de Kretser, R.G., Boger, D.V. and Scales, P.J. (1983) Compressive Rheology: An overview, Rheological Reviews 2003, Binding and Walters (eds), The British Society of Rheology, p. 1255.

Fisher, D.T., Scales, P.J. and Boger, D.V. (2007) The bucket rheometer for the viscosity characterization of yield stress suspensions, J. Rheol., 51(5), p. 82.

Fourie, A.B. (2007) Limitations to the use of the modified slump test for yield stress materials. Paste 2007: Proceedings of the Tenth International Seminar on Paste and Thickened Tailings, Fourie and Jewell (eds), Australian Centre for Geomechanics, Perth, Australia, p. 229.

Gladman, B., de Kretser, R.G., Rudman, M. and Scales, P.J. (2005) Effect of shear on particulate suspension dewatering, Chem. Eng. Research and Design, 83, pp. 933-936.

Gladman, B.J., Usher, S.P. and Scales, P.J. (2006) Understanding the Thickening Process. Paste 2006: Proceedings of the Ninth International Seminar on Paste and Thickened Tailings, Fourie and Jewell (eds), Australian Centre for Geomechanics, Perth, Australia

Gladman, B., Usher, S.P. and Scales, P.J. (2006) Compressive rheology of aggregated particulate suspensions, KoreaAustralia Rheology Journal, 18, pp. 191-197.

Jewell, R.J. (2006) Introduction, Paste and Thickened Tailings - A Guide, Second Edition, Jewell and Fourie (eds), Australian Centre for Geomechanics, Perth, Australia, p. 6.

Kreiger, I.M. and Maron, S.H. (1954) Direct determination of the flow curves of non-Newtonian fluids, III Standardised treatment of viscometric data, J Applied Physics 25(1), pp. 72-75.

Nguyen, Q.D. (1983) Rheology of concentrated bauxite suspensions, PhD Thesis, Monash University, Clayton.

Nguyen, Q.D. and Boger, D.V. (1983) Yield stress measurement for concentrated suspensions, J. Rheol., 27 , p. 321.

Nguyen, Q.D. and Boger, D.V. (1985) Direct yield stress measurement with the vane method, J. Rheol., 29 , p. 335.

Pashias, N. and Boger, D.V. (1996) A fifty-cent rheometer for yield stress measurement, J. Rheol., 40(6), p. 1179.

Pashias, N. (1997) The characterization of bauxite residue suspensions in shear and compression, PhD Thesis, The University of Melbourne.

Piau, J-M. (2005) Axisymmetric slump in spreading of cohesive plastic soft materials: a yield stress measurement by consisto-rheometry, J.Rheol. 49(6), pp. 1253-1276.

Sofra, F., Fisher, D.T. and Boger, D.V. (2007) The bucket rheometer for thickened tailings and paste flow curve determination. Paste 2007: Proceedings of the Tenth International Seminar on Paste and Thickened Tailings, Fourie and Jewell (eds), Australian Centre for Geomechanics, Perth, Australia, p. 249.

Usher, S.P. and Scales, P.J. (2005) Steady state thickener modeling from the compressive yield stress and hindered settling function, Chem. Eng. J., 111, pp. 253-261. 